\title{
DEXMEDETOMIDINE AND ROPIVACAINE IN THORACIC EPIDURAL ANAESTHESIA FOR BREAST SURGERY- A CLINICAL COMPARISON WITH GENERAL ANAESTHESIA
}

\author{
Harikrishna Dalai ${ }^{1}$, Chittaranjan Panigrahi' ${ }^{2}$, Dulal Kishun Soren ${ }^{3}$, Prakash Chandra Sahu4, Jaganath Panda 5 , Sapan Kumar Jena ${ }^{6}$, \\ Aparna Sahu ${ }^{7}$
}

\begin{abstract}
${ }^{1}$ Associate Professor, Department of Anaesthesiology and Critical Care, VSS Medical College and Hospital, (VIMSAR), Burla. ${ }^{2}$ Assistant Professor, Department of Anaesthesiology and Critical Care, VSS Medical College and Hospital, (VIMSAR), Burla. ${ }^{3}$ Associate Professor, Department of Anaesthesiology and Critical Care, VSS Medical College and Hospital, (VIMSAR), Burla. ${ }^{4}$ Postgraduate Trainee, Department of Anaesthesiology and Critical Care, VSS Medical College and Hospital, (VIMSAR), Burla. ${ }_{5}^{5}$ Postgraduate Trainee, Department of Anaesthesiology and Critical Care, VSS Medical College and Hospital, (VIMSAR), Burla. ${ }^{6}$ Postgraduate Trainee, Department of Anaesthesiology and Critical Care, VSS Medical College and Hospital, (VIMSAR), Burla. ${ }^{7}$ Postgraduate Trainee, Department of Anaesthesiology and Critical Care, VSS Medical College and Hospital, (VIMSAR), Burla.
\end{abstract}

\section{ABSTRACT}

\section{BACKGROUND}

General anaesthesia is the traditional standard technique for various breast surgery, but Thoracic Epidural Anaesthesia offers advantages like better haemodynamics, early recovery, less postoperative respiratory complications and good analgesia.

The objective of this study is to evaluate the effectiveness of Thoracic Epidural Anaesthesia with Dexmedetomidine and Inj. Ropivacaine $(0.5 \%)$ for breast surgery (MRM) with conventional general anaesthesia.

\section{MATERIALS AND METHODS}

With permission from Institutional Ethics Committee, forty consenting ASA Grades I and II patients posted for MRM were divided into two groups. In Group (TEA) Thoracic Epidural was performed in T4 - T8 intervertebral space and $5 \mathrm{~cm}$ of epidural catheter was threaded. Inj. Ropivacaine $0.5 \%$ with Dexmedetomidine $1 \mu \mathrm{g} / \mathrm{kg}$ was injected into the epidural space in increments via the catheter to achieve the desired height. In Group (GA), patients were managed in conventional way with Glycopyrrolate (0.2 mg), Fentanyl $(2 \mu \mathrm{g} / \mathrm{kg})$ and Midazolam $(0.05 \mathrm{mg} / \mathrm{kg})$ for premedication induced with Inj. Propofol $(2 \mathrm{mg} / \mathrm{kg})$. Intubation and maintenance of relaxation thereafter was with Vecuronium. Anaesthesia maintained with $\mathrm{N}_{2} 0: \mathrm{O}_{2}$ in 60:40 ratio with Isoflurane 0.4 - $0.6 \%$ in IPPV. Towards the end of surgery, the patients received Ondansetron (4 mg) and Diclofenac (75 mg) infusion and reversed with Neostigmine $(0.5 \mathrm{mg} / \mathrm{kg})$ and $20 \mu \mathrm{g}$ of Glycopyrrolate. Ringer's Lactate was used as maintenance fluid for both the groups. Monitoring of Pulse, NIBP, ECG, $\mathrm{SpO}_{2}$ and Respiration was done throughout surgery in both the groups.

\section{RESULTS}

Adequacy of anaesthesia, surgical condition, bleeding, post-anaesthesia recovery, untoward effects in the perioperative period and overall patient satisfaction were evaluated.

\section{CONCLUSION}

Thoracic epidural with $0.5 \%$ Ropivacaine in conjunction with Dexmedetomidine did offer an excellent perioperative outcome without any significant untoward effects.

\section{KEYWORDS}

Thoracic Epidural, Ropivacaine, Dexmedetomidine, General Anaesthesia, Breast Surgery.

HOW TO CITE THIS ARTICLE: Dalai H, Panigrahi C, Soren DK, et al. Dexmedetomidine and ropivacaine in thoracic epidural anaesthesia for breast surgery- a clinical comparison with general anaesthesia. J. Evolution Med. Dent. Sci. 2017;6(26):2149-2153, DOI: $10.14260 /$ Jemds/2017/466

\section{BACKGROUND}

Awareness among the population and early detection of breast malignancies has resulted in increased surgical interventions like lumpectomy, breast conservation therapy, modified radical mastectomy, etc. Psychological and surgical stress can lead to cardiovascular changes and hypercoagulable state in the body.[1-8] This can be

Financial or Other, Competing Interest: None.

Submission 21-02-2017, Peer Review 16-03-2017,

Acceptance 23-03-2017, Published 30-03-2017.

Corresponding Author:

Dr. Harikrishna Dalai

Associate Professor,

Department of Anaesthesiology and Critical Care,

VSS Medical College AND Hospital (VIMSAR),

Burla, Sambalpur-768017, Odisha.

E-mail:drhkdalai@gmail.com

DOI: $10.14260 /$ jemds $/ 2017 / 466$

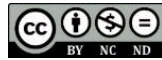

mitigated by General Anaesthesia (GA) as well as regional anaesthesia techniques like Thoracic Epidural Anaesthesia (TEA), Paravertebral blocks, Intercostal blocks, Field blocks, Pec 1 and Pec 2 blocks. Regional anaesthesia techniques provide better haemodynamic stability, early recovery, less postoperative respiratory complications and good intraoperative as well as postoperative analgesia.[4-14] However, most of the regional anaesthesia techniques mentioned above have certain limitations in comparison to TEA, which is being used extensively for various breast procedures with or without GA. Besides, in surgical procedures under regional anaesthesia, intra-operative consciousness and awareness among patients remains a major drawback. Dexmedetomidine hydrochloride, an [ $\alpha-2]$ agonist has properties of sedation, analgesia and anxiolysis. ${ }^{[15-19]}$ At present it is being used a lot for sedation in ICU and to provide monitored anaesthesia care during different medical and surgical procedures and as an adjuvant 
to local anaesthetics in different blocks. This study was carried out to evaluate the efficacy of Dexmedetomidine as an adjuvant to Ropivacaine in TEA.[15-20] for breast surgery.

\section{MATERIALS AND METHODS}

Approval of the Ethical Committee was obtained. Considering a confidence level of $90 \%$ and a power of $80 \%$, hypothesised difference of 15 , our sample size was calculated to be 17 ; and basing on reports of similar studies, forty female patients of ASA Grades I - II, aged 25 - 60 years were selected and divided randomly into two groups TEA and GA comprising of twenty each. Randomisation was done by draw of cards, after obtaining their informed written consent. All contraindications pertaining to central neuraxial blocks were considered as exclusion criteria including allergy to drugs used for this study.

On the night before surgery, patients in both the groups were advised to take Tab. Lorazepam (2 mg) and Tab. Ranitidine (150 mg) and were advised to be nil per os after midnight. On the day of surgery, an intravenous line with 18G cannula was set and a Ringer's Lactate drip was started. Monitors were attached and baseline values were recorded.

Patients in Group GA were premedicated with Inj. Glycopyrrolate $0.2 \mathrm{mg}$, Inj. Midazolam $0.05 \mathrm{mg} / \mathrm{kg}$ and Inj. Fentanyl $2 \mu \mathrm{g} / \mathrm{kg}$. Patients were induced with Inj. Propofol 2 $\mathrm{mg} / \mathrm{kg}$. Orotracheal intubation was facilitated with Inj. Vecuronium $0.1 \mathrm{mg} / \mathrm{kg}$. After ascertaining the proper placement of tube, cuff was inflated and tube was fixed. Anaesthesia was maintained with $\mathrm{N}_{2} \mathrm{O}: \mathrm{O}_{2}$ in a ratio of 60:40 with Isoflurane at $0.4-0.8 \%$ in volume controlled mode with a tidal volume of $500 \mathrm{~mL}$ and rate of 14 breaths/min. Intraoperative relaxation was maintained with incremental dose of Vecuronium $1 \mathrm{mg}$. Ringer's Lactate was the only fluid used for maintenance. Towards the end of surgery, patients were given Inj. Diclofenac $75 \mathrm{mg}$ in infusion and Inj. ondansetron $4 \mathrm{mg}$ slow IV, residual paralysis was reversed with $0.05 \mathrm{mg} / \mathrm{kg}$ of Inj. Neostigmine and $0.02 \mu \mathrm{g}$ of Inj. Glycopyrrolate. The patients were extubated after ascertaining complete reversal of neuromuscular block.

In the TEA Group, Epidural space was identified with an 18G Tuohy needle in T4 - T8 intervertebral space by LOR technique with saline in the sitting position and $5 \mathrm{cms}$ of epidural catheter was threaded. Proper placement of epidural catheter was confirmed by negative aspiration and with administration of $3 \mathrm{~mL}$ of Inj. Lignocaine $2 \%$ with Adrenaline. After fixation of the catheter, patients were made supine. Inj. Ropivacaine $0.5 \%$ with Inj. Dexmedetomidine $1 \mu \mathrm{g} / \mathrm{kg}$ was injected at a volume of $1 \mathrm{~mL} /$ segment into the epidural space in increments. Surgery was allowed to start after confirmation of block from subcostal margin below to infraclavicular fossa above. The patients were administered Oxygen at a flow rate of $6 \mathrm{~L} / \mathrm{min}$ by Hudson's face mask. Patients received Ringer's Lactate solution at a rate of 8 $\mathrm{mL} / \mathrm{kg} / \mathrm{hr}$ for coloading and as maintenance fluid.

In both the groups continuous monitoring of pulse, noninvasive blood pressure, ECG, oxygen saturation and respiration were done in the intraoperative period and the values were recorded. Any rise or fall in blood pressure \pm $20 \%$ from the baseline was considered as hypertension/hypotension. Hypotension was treated with Inj. Ephedrine $5 \mathrm{mg}$ IV in increments. Fall in heart rate below 60 bpm was considered as bradycardia and was treated with Inj.
Atropine $0.3 \mathrm{mg}$ IV. Hypertension and tachycardia was controlled by vasodilators and/or by increasing the concentration of isoflurane.

Subjective assessment of blood loss and quality of surgical condition was made from the operating surgeon's feedback. The postoperative discharge criteria were assessed basing on Aldrete score at first and second hour and a score of $9 / 10$ was considered adequate for discharge from the postanaesthesia recovery room, the patient satisfaction score was assessed by The IOWA Satisfaction with Anaesthesia Scale (ISAS), a self-administered questionnaire for evaluating a Patient's satisfaction with monitored anaesthesia care received.

Inj. Diclofenac sodium $75 \mathrm{mg}$ IM was used as rescue analgesic in either of the groups in the postoperative period.

Statistical analysis was done by using SPSS 17 Software with suitable tables. Chi square test and student's ' $t$ ' test were performed for qualitative and quantitative estimation of the test for significance and $\mathrm{p} \leq 0.05$ was considered significant.

\begin{tabular}{|c|c|c|}
\hline Demographic Profile & Group TEA & Group GA \\
\hline Age (Yrs.) & $50.8 \pm 12.11$ & $51.28 \pm 9.5$ \\
\hline Height (cms) & $150.04 \pm 4.9$ & $152.38 \pm 4.6$ \\
\hline Duration of Surgery (min) & $118.02 \pm 3.2$ & $115.41 \pm 3.9$ \\
\hline Baseline Systolic BP & $124.10 \pm 9.94$ & $122.07 \pm 9.35$ \\
\hline Baseline Diastolic BP & $76.53 \pm 5.50$ & $75.33 \pm 4.4$ \\
\hline Baseline Heart Rate & $84 \pm 4.48$ & $83 \pm 5.42$ \\
\hline \multicolumn{3}{|c|}{ Table 1. Demographic Profile (Mean \pm SD) } \\
\hline
\end{tabular}

${ }^{*} \mathrm{p} \geq 0.05$

\begin{tabular}{|c|c|c|}
\hline & Group TEA & Group GA \\
\hline Hypotension & $3(15 \%)$ & $1(5 \%)$ \\
\hline Hypertension & $0(0 \%)$ & $5(25 \%)^{*}$ \\
\hline Bradycardia & $5(25 \%)^{*}$ & $2(10 \%)$ \\
\hline Tachycardia & $0(0 \%)$ & $4(20 \%)$ \\
\hline Table 2. Incidences of Intraoperative \\
Haemodynamic Variations \\
\hline
\end{tabular}

${ }^{*} \mathrm{p} \leq 0.05$

\begin{tabular}{|c|c|c|}
\hline Parameter & Group TEA & Group GA \\
\hline Nausea and Vomiting & $3(15 \%)^{*}$ & $12(60 \%)^{*}$ \\
\hline $\begin{array}{c}\text { Respiratory } \\
\text { Distress/Discomfort }\end{array}$ & 0 & $2(10 \%)$ \\
\hline Dural Puncture & 0 & 0 \\
\hline Hypotension & $2(10 \%)$ & $4(20 \%)$ \\
\hline Bradycardia & $5(25 \%)$ & $2(10 \%)$ \\
\hline Shivering & $1(5 \%)$ & $2(10 \%)$ \\
\hline Aldrete Score @ 1 hr (> 9/10) & $17(85 \%)^{*}$ & $12(60 \%)^{*}$ \\
\hline Aldrete Score @2 hrs. (> 9/10) & $20(100 \%)$ & $17(85 \%)$ \\
\hline \multicolumn{2}{|c|}{ Table 3. Postoperative Observations } \\
\hline
\end{tabular}

$* \mathrm{p} \leq 0.05$

\begin{tabular}{|c|c|c|}
\hline $\begin{array}{c}\text { Postop Time } \\
\text { Interval }\end{array}$ & Group TEA & Group GA \\
\hline At 0 hrs. & $2.4^{*}$ & $5.8^{*}$ \\
\hline 8 hrs. & $3.2^{*}$ & $5.2^{*}$ \\
\hline 16 hrs. & 3.8 & 4.1 \\
\hline 24 hrs. & 4.1 & 3.8 \\
\hline \multicolumn{2}{|c|}{ Table 4. Postoperative VAS Score (Mean) } \\
\hline
\end{tabular}

${ }^{*} \mathrm{p} \leq 0.05$ 


\begin{tabular}{|c|c|c|}
\hline Group & Satisfied & Not Satisfied \\
\hline TEA & $17(85 \%)$ & $3(15 \%)$ \\
\hline GA & $16((80 \%)$ & $4(20 \%)$ \\
\hline \multicolumn{3}{|c|}{ Table 5. Surgeon's Observation } \\
\hline
\end{tabular}

\begin{tabular}{|c|c|c|}
\hline Group & Satisfied & Not Satisfied \\
\hline TEA & $18(90 \%)$ & $2(10 \%)$ \\
\hline GA & $16(80 \%)$ & $4(20 \%)$ \\
\hline \multicolumn{3}{|c|}{ Table 6. Patient's Opinion } \\
\hline
\end{tabular}

\begin{tabular}{|c|c|}
\hline Group TEA & $29 / 33(87.87 \%)$ \\
\hline Group GA & $22 / 33(66.66 \%)$ \\
\hline \multicolumn{2}{|c|}{ Table 7. IOWA Satisfaction with } \\
Anaesthesia Scale (ISAS) Score
\end{tabular}

\section{RESULTS}

The demographic picture and the baseline variables in both the groups were found to be similar (Table 1) and without any significance

The incidence of Bradycardia in the intraoperative period was found to be significantly high $(25 \%)$ in Group TEA, while the incidence of Hypertension (25\%) was remarkable in the GA Group. The surgical site bleeding was more in GA group as assessed by the operating surgeons, but they considered it to be acceptable. Apart from these there was not a significant variation in the haemodynamics in either of the groups. (Table 2) Remarkably significant incidence of nausea and vomiting was observed in GA (60\%) group, occurrence of shivering (10\%) and respiratory discomfort (10\%) were also observed more in GA Group in comparison to the TEA group. Bradycardia (25\%) was observed in the TEA Group. The incidence of shivering and respiratory discomfort, hypertension were high, but were statistically not significant in GA group. Aldrete score which was significant in Group TEA (85\%) in the first hour as compared to the GA group $(60 \%)$ after the discontinuation of anaesthetics. At the end of two hours the scores in TEA group was (100\%) compared to $(85 \%)$ in GA group, which was not significant (Table 3). Pain control was better in Group TEA with a significantly low mean VAS score of (2.4 at 0 hrs. and 3.2 at $8 \mathrm{hrs}$.) as compared to the Group GA (5.8 and 5.2 in the respective period) postoperatively. The decrease in VAS score in Group GA towards $16 \mathrm{hrs}$. and $24 \mathrm{hrs}$. could be attributed to the effect of rescue analgesic used for pain control in the immediate postoperative period. The overall requirement of rescue analgesics was far less in the TEA group compared to GA group. The mean VAS score was quite less in the TEA group overall in the first twenty four hours (Table 4). There was not much difference considering the feedbacks given by the surgeons (85\% in TEA group and $80 \%$ in GA group were satisfied) regarding bleeding and quality of surgical field in either of the groups (Table 5). Patients in both the groups seemed to be quite comfortable and satisfied $(90 \%$ in TEA and $80 \%$ in the GA group were satisfied) in the techniques. The IOWA satisfaction score was of not much significance in either of the groups, as the patients of both the groups ( $87.87 \%$ in TEA and $66.66 \%$ in GA group) were comfortable (Table 7).

\section{DISCUSSION}

In spite of advancement in various regional techniques for breast surgery general anaesthesia is still the preferred technique by many of the practitioners as well as the patients, a combination of general anaesthesia with a thoracic epidural for postoperative pain relief is also a standard by most of the surgical teams, hence an attempt was made to evaluate the feasibility of using thoracic epidural with dexmedetomidine and ropivacaine $[13,19,21,22]$ as the sole technique for the complete procedure. It is seen that epidural technique imparts a better haemodynamic stability and perioperative outcome.[4-14] Psychological or physical stress manifests its effects like hypercoagulability by enhancing the procoagulable state.[1,2] This can also lead to plaque instability and acute coronary syndrome.[2,3,6,7] Thoracic epidural causes a selective chemical sympathectomy provides segmental block which can attenuate the stress response and this segmental block is compensated by the sympathetic overactivity by the unblocked segments.[4-7] Also the stress of laryngoscopy and intubation is avoided, as this can add to the stress response and its hazards during general anaesthesia and intubation. TEA also increases the repolarisation refractoriness of the myocardium thus preventing arrhythmia, maintains the myocardial demand/supply ratio and coronary perfusion pressure in the ischaemic myocardium, thus optimising the myocardial oxygen delivery and decreasing the cardiac work and benefitting the cardiovascular status[6,7,9,8] by its positive effects on respiratory system $[9,8,10]$ and minimal change in ventilatory mechanics even in chronic obstructive respiratory disease and prevents perioperative adverse events.[10-14,20,23] TEA with ropivacaine and dexmedetomidine improves the quality of block, increases the duration of block while decreasing the latency period, imparts better anxiolysis, sedation and analgesia minimises the requirement of analgesic and sedative supplement during axillary node clearance.[15-18,21] In this study, it was observed that the haemodynamic and respiratory pattern was better, our findings were similar to the findings of A Clemente et al, ${ }^{[8]}$ Salgado PF et al in their study had reported synergistic effect of Ropivacaine with Dexmedetomidine in epidural anaesthesia, which might be a reason for non-supplementation of sedative or analgesics in TEA group in our study, some cases of hypotension and bradycardia were observed which were well managed by ephedrine and atropine. The patients in TEA group had less incidence of postoperative nausea and vomiting, Borgeat $A$ et al[24] in their study too had mentioned about lesser incidence of nausea and vomiting in epidural anaesthesia with ropivacaine and alpha- 2 agonist clonidine. ${ }^{[24]}$ There was less incidence of shivering observed in our study in the TEA group, which can be attributed to the effect of dexmedetomidine. These findings corroborates to the study of Grewal A,[15] Parnjape JS[16] and Maroof A.[19] In the postoperative period our patients had less incidence of pain, which might be due to the effect of dexmedetomidine and ropivacaine, Grewal A,[15] Salgado PF et al[19] Paranjpe JS].[16] This could have extended into the second postoperative day too with the catheter in situ, but it was not in our study design so was not assessed.[15-18,21,22,25] Bajwa SJ et al,[17] Martha $V$ et al,[18] Salgado PF et al and Arunkumar $S$ et al[21] in their studies on alpha-2 agonists had demonstrated the beneficial effects of dexmedetomidine when used in conjunction with ropivacaine for epidural anaesthesia. Our findings also demonstrated similar facts.

TEA may have some beneficial effect on postoperative scar and phantom breast pain, but it was beyond the scope of 
this study so could not be assessed, Kroner $\mathrm{K}$ et al.[26] The quicker recovery pattern than GA group is also established and reported owing to the typical effect of dexmedetomidine, which causes conscious sedation and lack of respiratory depression.[11,15,16,21,23] Early recovery and discharge can decrease the load on caregivers at PACU and minimise the financial burden on the health system. The patient satisfaction though was not statistically significant, but more number of patients (87.87\%) were satisfied with the technique.[27] This may be due to the effect of dexmedetomidine imparting its sedative, hypnotic and analgesic effect during the procedure.[15,16] Addition of dexmedetomidine can extend the scope of TEA to elderly patients with comorbidities (though it could not be studied as the study was on ASA I-II patients) due to its inherent properties of sedation, analgesia and least effect on cardiorespiratory system in therapeutic dose and its synergistic effect with ropivacaine as has been studied by various authors.[13,14,15,16,19]

\section{CONCLUSION}

Thoracic epidural anaesthesia with ropivacaine and dexmedetomidine is a safe and reliable alternative as the sole anaesthetic to general anaesthesia, for breast surgery owing to better cardiorespiratory stability, perioperative analgesia and lesser incidence of shivering and nausea and vomiting.

\section{Limitations}

A bigger sample size will validate our findings, so further multicentric trials are awaited. Patients with comorbidity and elderly patients and patients having comorbidity were not evaluated in the study.

\section{REFERENCES}

[1] Kanel VR, Mills PJ, Ziegler MG, et al. Effect of beta2adrenergic receptor functioning and increased norepinephrine on the hypercoagulable state with mental stress. Am Heart J 2002;144(1):68-72.

[2] Sambola A, Osende J, Hathcock J, et al. Role of risk factors in the modulation of tissue factor activity and blood thrombogenicity. Circulation 2003;107(7):9737.

[3] Gidron Y, Gilutz H, Berger R, et al. Molecular and cellular interface between behavior and acute coronary syndromes. Cardiovasc Res 2002;56(1):1521.

[4] Waurick R, Aken VH. Update in thoracic epidural anaesthesia. Best Pract Res Clin Anaesthesiol 2005;19(2):201-13.

[5] Baron JF, Payen D, Coriat P, et al. Forearm vascular tone and reactivity during lumbar epidural anaesthesia. Anesth Analg 1988;67(11):1065-70.

[6] Meissner A, Eckardt L, Kirchhof P, et al. Effects of thoracic epidural anesthesia with and without autonomic nervous system blockade on cardiac monophasic action potentials and effective refractoriness in awake dogs. Anesthesiology 2001;95(1):132-8.

[7] Blomberg S, Emanuelsson H, Kvist H, et al. Effects of thoracic epidural anesthesia on coronary arteries and arterioles in patients with coronary artery disease. Anesthesiology 1990;73(5):840-7.
[8] Clemente A, Carli F. The physiological effects of thoracic epidural anesthesia and analgesia on cardiovascular, respiratory and gastrointestinal systems. Minerva Anesthesiol 2008;74(10):549-63.

[9] McLeod GA, Cumming C. Thoracic epidural anaesthesia and analgesia. Continuing education in anaesthesia, critical care \& pain 2004;4(1):16-9.

[10] Sakura S, Saito Y, Kosaka Y, et al. The effect of epidural anesthesia on ventilatory response to hypercapnia and hypoxia in elderly patients. Anesth Analg 1996;82(2):306-11.

[11] Lynch EP, Welch KJ, Carabuena JM, et al. Thoracic epidural anesthesia improves outcome after breast surgery. Ann Surg 1995;222(5):663-9.

[12] Yeh CC, Yu JC, Wu CT, et al. Thoracic epidural anesthesia for pain relief and postoperation recovery with modified radical mastectomy. World J Surg 1999;23(3):256-60.

[13] Salgado PF, Sabbag AT, Silva PC, et al. Synergistic effect between dexmedetomidine and $0.75 \%$ ropivacaine in epidural anesthesia. Rev Assoc Med Bras 2008;54(2):110-5.

[14] Gruber EM, Tschernko EM, Kritzinger M, et al. The effects of thoracic epidural analgesia with bupivacaine $0.25 \%$ in ventilator mechanics in patients with severe chronic obstructive pulmonary disease. Anesth Analg 2001;92(4):1015-9.

[15] Grewal A. Dexmedetomidine: new avenues. J Anaesthesiol Clin Pharmacol 2011;27(3):297-302.

[16] Lahiry S, Sharma DN, Mund M, et al. Thoracic epidural versus general anaesthesia for MRM surgeries. Int J Med and Dent Sci 2016;5(2):1125-31.

[17] Bajwa SJ, Bajwa SK, Kaur J, et al. Dexmedetomidine and clonidine in epidural anaesthesia: a comparative evaluation. Indian J Anaest 2011;55(2):116-21.

[18] Maratha V, Kapil M, Kumar S, et al. Comparative evaluation of ropivacaine versus dexmedetomidine and ropivacaine in epidural anesthesia in lower limb orthopaedic surgeries. IAIM 2016;3(10):36-41.

[19] Maroof M. Evaluation of effect of dexmedetomedine in reducing shivering following epidural anesthesia. ASA annual meeting. Abstract: A49.

[20] Doss NW, Ipe J, Crimi T, et al. Continuous thoracic epidural anesthesia with $0.2 \%$ ropivacaine versus general anesthesia for perioperative management of modified radical mastectomy. Anesth Analg 2001;92(6):1552-7.

[21] Arunkumar S, Kumar VRH, Krishnaveni N, et al. Comparison of dexmedetomidine and clonidine as an adjuvant to ropivacaine for epidural anesthesia in lower abdominal and lower limb surgeries. Saudi J Anaesth 2015;9(4):404-8.

[22] Paranjpe JS. Dexmedetomidine: expanding role in anesthesia. Med J DY Patil Univ 2013;6(1):5-13.

[23] Liu S, Carpenter RL, Neal JM. Epidural anesthesia and analgesia. Their role in postoperative outcome. Anesthesiology 1995;82(6):1474-506.

[24] Borgeat A, Ekatodramis G, Schenker CA. Postoperative nausea and vomiting in regional anesthesia: a review. Anesthesiology 2003;98:530-47. 


\section{Jemds.com}

[25] Block BM, Liu SS, Rowlingson AJ, et al. Efficacy of postoperative epidural analgesia: a meta-analysis. JAMA 2003;290(18):2455-63.

[26] Kroner K, Knudsen UB, Lundby L, et al. Long-term phantom breast syndrome after mastectomy. Clin J Pain 1992;8(4):346-50.

\section{Original Research Article}

[27] Dexter F, Aker J, Wright WA. Development of a measure of patient satisfaction with monitored anaesthesia care: the lowa satisfaction with anesthesia scale. Anesthesiology 1997;87(4):865-73. 